\title{
ATRAUMATIC SURGICAL EXTRUSION OF COMPLETE CROWN FRACTURED TOOTH USING PERIOTOME IN ESTHETIC ZONE: REPORT OF THREE CASES
}

Prashant Bhusari¹, Shiras Verma², Amiyavardhan Jain³, Nitin Agrawal'4, Shivam Upadhyay5

\section{HOW TO CITE THIS ARTICLE:}

Prashant Bhusari, Shiras Verma, Amiyavardhan Jain, Nitin Agrawal, Shivam Upadhyay. "Atraumatic Surgical Extrusion of Complete Crown Fractured Tooth using Periotome in Esthetic Zone: Report of Three Cases". Journal of Evolution of Medical and Dental Sciences 2014; Vol. 3, Issue 23, June 09; Page: 6550-6558, DOI: $10.14260 /$ jemds/2014/2780

ABSTRACT: BACKGROUND: Restoring traumatically injured teeth is a clinical challenge and often requires a multidisciplinary approach for predictable esthetic outcome. Although a number of techniques have been proposed for clinical crown lengthening procedures, all have some limitations in terms of function and esthetic. AIM: This report presents the clinical and radiographic results of surgical extrusion technique for clinical crown lengthening. MATERIAL \& METHODS: Atraumatic surgical extrusion using a specially designed instrument (Periotome) was performed in three cases in which it was expected that extensive respective osseous surgery would have to be used for crown lengthening. After luxation the teeth were extruded to the desired position and stabilized with sutures without rigid splinting. Two months after stabilization the teeth were treated by root canal treatment and firmly restored after 4months. RESULTS: Clinical examination performed after 6 months revealed probing depth $\leq 3 \mathrm{~mm}$ around the teeth at all sites without bleeding on probing. Radiographs showed normal periodontal contour with new bone formation in periapical region without any evidence of root or crestal bone resorption or endodontic problems. CONCLUSION: The outcome of the treatment within a short duration has very good results without any esthetic and functional deformities.

KEYWORDS: Biologic width, crown lengthening, extrusion, esthetics, periodontal splint.

INTRODUCTION: Crown lengthening is a common and important procedure in dental practice. The basic principle of surgical extrusion technique is to place the affected tooth structure in a more desired position which helps in reestablishment of biologic width free of any invasive restorative dentistry, caries, fracture \& endodontic perforation circumferentially around the tooth. ${ }^{1,2}$ Invasion of biologic width can create serious consequences to the periodontium challenging marginal homeostasis so that its recovery becomes critical.

Several techniques have been proposed for clinical crown lengthening such as gingivectomy, apically-positioned flap with or without resective osseous surgery and orthodontic forced eruption with or without fibrotomy. ${ }^{3}$ The selection of one technique over another depends on several patientrelated factors:(1) esthetics, (2) clinical crown-to-root ratio,(3) root proximity, ${ }^{(4)}$ root morphology,(5) furcation location,(6) individual tooth position,(7) collective tooth position and(8) ability to restore the tooth. 4,5

There are clinical situations where the conditions are unfavorable for surgical and restorative procedures. Often in cases of deep subgingivally located caries and tooth fracture, extensive resective osseous surgery may result in increased pocket depth and mobility, furcation involvement, poor crown-to-root ratio and loss of supporting tissue of neighboring teeth. ${ }^{6}$ When choosing surgical crown lengthening in the esthetic zone, extreme care should be taken because it will often result in 
asymmetry of the gingival margin. ${ }^{7}$ Preservation of gingival margin and interdental papilla is required in order to obtain satisfactory esthetic outcome. ${ }^{8}$

Orthodontic forced eruption with or without repeated fibrotomy overcomes these disadvantages. However these procedures are more cumbersome than surgical crown lengthening because of the necessity of a surgical and retention phase of clinical crown lengthening after orthodontic forced eruption, need for several session of fibrotomy to prevent the periodontal tissue from being pulled coronally together with the orthodontically moving root and relapse tendency. ${ }^{9}$

To treat teeth with deep cervical root fracture and deep cervical root caries that are difficult to treat conservatively, the surgical extrusion technique has been proposed, with predictable shortand long term results. ${ }^{10,11}$ Occasionally apical root resorption and marginal bone loss are observed phenomenon suspected to be induced by surgical trauma. ${ }^{10}$

The purpose of this case series is to report three cases wherein atraumatic surgical extrusion by using a specially designed instrument (Periotome Fig) was performed in which it was expected that extensive resective osseous surgery would have to be used for crown lengthening. All the three cases were followed clinically and radio graphically for 6 months with no esthetic and functional deformities.

\section{CASE PRESENTATION:}

Case 1: A 34 years male patient presented with extensive subgingival caries in cervical one third of the root portion compromising biologic width in mandibular right canine. Radiologic examination revealed no periapical lesion and no periodontal breakdown (Fig. 1-a, b).

Case 2: A healthy 27years non-smoking male presented with complaint of horizontal fracture of maxillary lateral incisor. Clinical and radiographic examination revealed that the fracture margin was situated subgingivally and extended almost to the alveolar crest on the palatal aspect. Endodontic treatment was carried out 3 months before and then patient was referred for clinical crown lengthening procedure (Fig. 2-a).

Case 3: A 24years male patient was referred to the Department of Periodontology, Modern Dental College and Research Center, Indore, India for crown lengthening. Clinical and radiographic examination depicted biologic width compromised by the subgingival root remnants, no previous endodontic treatment and periapical lesion with no periodontal breakdown (Fig 3-a).

In all the above cases the decision was made to perform surgical extrusion for clinical crown lengthening and endodontic treatment after 2 months with subsequent crown placement. Patients consent was taken after explaining the advantages of this procedure over other procedures and the surgical protocol was approved by the ethical committee of the institution.

CASE REPORTS: The surgical technique used for crown lengthening and to treat the teeth with compromised biologic width involved the following steps:

1. Infiltration anaesthetics.

2. Dental caries removal.

3. Intracrevicular incision, including the medial and distal papillae. 
4. Reflection of full-thickness buccal and lingual flaps up to the bone crest, with no relieving incision and preserving all the soft tissue.

5. Measurement of distance of the tooth margin from the surrounding bone crest to calculate the amount of extrusion necessary.

6. Luxation of the tooth with the help of Periotome, i.e. by putting the blade of Periotome into the periodontal ligament space of the tooth to be treated and manipulating it in walking motion to luxate the tooth without inducing surgical trauma.

7. Extrusion of the tooth to the desired position using hemostat.

8. Closure of flap and fixation of tooth by simple interrupted sutures.(No use of rigid splint).

9. Endodontic treatment followed by crown placement 2 months after surgical treatment.

Patients were instructed to rinse with $0.12 \%$ chlorhexidine solution during the first 2 weeks following surgery. Antibiotics regimens, Amoxicillin $500 \mathrm{mg}$, one capsule every 8hours for 7 days and acetaminophen 750, one tablet every 6 hours for 2 days were prescribed. The sutures were removed after 14 days. Patients were checked every 1 or 2 weeks for the first 2 months and then once a month for the following 6 months. Radiographic and clinical examinations were performed to assess changes in periapical and periodontal healing, probing depth and mobility.

Post-operative tooth mobility after first week was marked but decreased gradually during the second week (Fig. 1-b, Fig. 2-b). Clinically, minimal gingival inflammation and tooth mobility were evident after 4 weeks (Fig. 1-c). The immediate post-operative radiographs showed empty, radiolucent space around apical area (Fig. 1-d). However, an increase in radiographic density suggesting new bone formation was observed around the periapical area at the 2 months examination (Fig. 1-e). Endodontic treatment followed by crown treatment was performed 2 months after the surgery (Fig.-f \& Fig. -g, Fig. 2-c, Fig. 3-b). Clinical examination 3 months after surgery revealed probing depth $\leq 3 \mathrm{~mm}$ around the tooth at all sites, without bleeding on probing.

A periapical radiograph showed a radiopaque periapical area consistent with new bone formation and normal periodontal ligament space (Fig. 1-g). The tooth functioned normally, with near-normal mobility after 6 months (fig. 1-h, Fig. 2-d, Fig.-3-c). Radiographic analysis did not show any evidence of root resorption, crestal bone resorption, or endodontic problems. There was almost $3-4 \mathrm{~mm}$ increase in the clinical crown length in every case maintaining crown: root ratio of 1:1 which helped in preparing the retaition form. All the 3 patients were very satisfied about the atraumatic \& less painful surgical procedure and for restoration of esthetics \& functions.

DISCUSSION: The treatment of teeth considered condemned to extraction because of fracture, extensive caries or other factors that cause loss of dental substance in the area of biologic width should be reviewed stressing the benefit of tooth survival to the overall periodontal and general health. Clinical crown lengthening in esthetic areas requires a more reliable and sophisticated diagnostic process and treatment modality selection. ${ }^{12}$

The surgical extrusion technique for clinical crown lengthening described here was successful from both esthetic and functional point of view since resective osseous surgery was not done. Several studies had demonstrated the clinical feasibility of surgical extrusion with favorable short and longterm results, and suggest that this method is much more economical than implant or fixed partial denture treatment. ${ }^{10,11}$ 
The evaluation of periodontal repair on transplanted or surgically extruded teeth usually shows slight marginal bone and apical root resorption. ${ }^{13}$ Apical root resorption is observed more frequently when osseous grafts are used periapically for stabilization. ${ }^{14}$ Although the exact mechanism of this phenomenon is not fully understood, the two possible factors such as surgical trauma during luxation of $\operatorname{root}^{10}$ and dehydration of the Periodontal Ligament ${ }^{10,14}$ (PDL) may be contributing to marginal bone and apical root resorption.

None of the cases presented in this article showed the marginal bone or apical root resorption as we employed a Periotome which was specially designed for atraumatic extraction or luxation and the root never left the socket during surgical procedure thus avoided/minimized risk of dehydration of PDL.

Interestingly tooth mobility was minimal after 4 weeks and there was radiographic evidence of new periapical bone formation as early as 2 months postoperative. Additionally no endodontic problem was found. In the second case there was pulp necrosis before surgical procedure. Endodontic treatment was performed 3 weeks before the surgical procedure. Since endodontically treated teeth are more susceptible to longitudinal root fracture because of the friability and fragility, surgical extrusion/luxation was carried out very delicately without causing damage to the tooth structure.

The fixation of the extruded teeth was accomplished only by sutures (semi-rigid splint) (Fig-. This method seems to allow for some mobility, thus allowing functional stimulation throughout the healing period. Slight mobility during the fixation period is said to be favorable for the prognosis by preventing ankylosis and resorption. ${ }^{15,16}$ Clinically stable mobility was achieved within first month and maintained during the observation period. No relapse tendency was observed. These observations may corroborate prior studies about the healing of transplanted teeth using non-rigid fixation technique. $9,10,12,16$

CONCLUSION: The clinical findings presented here suggest that this protocol offers several advantages over the conventional surgical approaches and can be used successfully to treat severely damaged tooth without functional and esthetic deformities, especially in the anterior region where esthetic is of great concern.

\section{REFERENCES:}

1. Chandler KB, Rongey WF. Forced eruption: Review and case reports. Gen Dent 2005; 53: 274277.

2. Segelnick SL, Uddin M, Moskowitz EM. A simplified appliance for forced eruption. J Clin Orthod 2005; 39: 432-434.

3. Lanning SK, Waldrop TC, Gunsolley JC, Maynard JG. Surgical crown lengthening: Evaluation of bialogic width. J Periodontol 2003; 74: 468-474.

4. Levine RA. Forced eruption in the esthetic zone. Compend Contin Educ Dent1997; 18: 795-803.

5. Bensimon GC. Surgical crown lengthening procedure to enhance esthetics. Int J Periodontics Restorative Dent 1999; 19: 332-341.

6. Kohavi D, Stern N. Crown lengthening procedure. Part II. Treatment planning and surgical considerations. Compend Contin Educ Dent 1983; 4: 413-419.

7. Rosenblatt A, Simon Z. Lip repositioning for reduction of excessive gingival display: A clinical report. Int J Periodontics Restorative Dent 2006; 26: 433-437. 
8. Kim SH, Tramontina V, Passanezi E. A new approach using the surgical extrusion procedure as an alternative for the reestablishment of biologic width. Int J Periodontic Restorative Dent 2004; 24: 39-45.

9. Bragger U, Lauchenauer D, Lang NP. Surgical lengthening of clinical crown. J Clin Periodontol 1992; 19: 58-63.

10. Kahnberg KE. Intraalveolar tranplantation. I A 10 year follow-up of a method for surgical exrrusion of root fractured teeth. Swed Dent J 1996; 20: 165-172.

11. Caliskan MK. Surgical extrusion of cervically root-fractured tooth after apexification treatment. J Endo 1999; 25: 509-513.

12. Dibart S, Capri D, kachouh I, Van Dyke T, Nunn ME. Crown lengthening in mandibular molars: A 5 year retrospective analysis. J Periodontol 2003; 74: 815-821

13. Andreasen JO, Kristersen L. Effect of extra-alveolar root filling with calcium hydroxide on periodontal healing after replantation of permanet incisors in monkeys. J Endod 1981; 7: 349354.

14. Kahnberg KE, Warfvinge J, Birgersson B. Intraalveolar transplantation. (I) The autogenous bone transplants in the periapical region. Int J Oral Surg 1982; 11: 372-379.

15. Ram D, Cohenca N. Therapeutic protocols for avulsed permanent teeth: review and clinical update. Pediatr Dent 2004; 26: 251-255.

16. Magheri P, Grandini P, Cambi S. Autogenous dental transplant: Description of a clinical case. Int J Periodontics Restorative Dent 2001; 21: 367-371.

\section{Case 1:}

Fig. a) Initial clinical view of lower right canine shows subgingival fracture margin \& complete loss of crown.

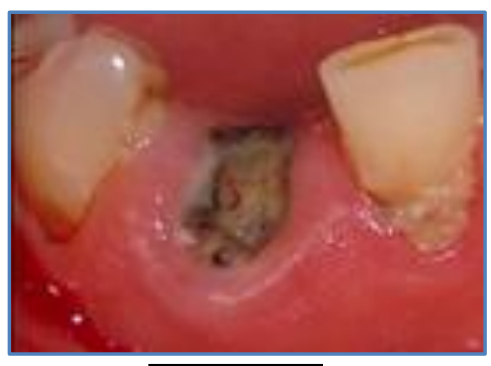

Fig. a

Fig. b) Buccal view of coronally positioned root \& tight interproximal sutures for maintaining stability.

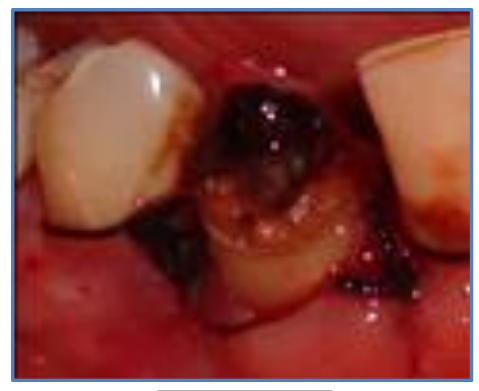

Fig. $\mathbf{b}$ 


\section{CASE REPORT}

Fig. c) Two months post-surgically.

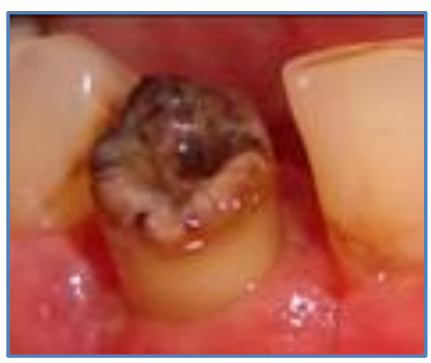

Fig. c

Fig. d) Buccal view of canine after reconstruction with core \& post.

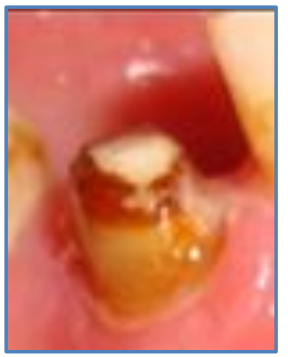

Fig. d

Fig. e) Pre- operative radiograph shows no evidence of interdental and periapical bone loss but too deep compromise of tooth leading to poor prognosis.

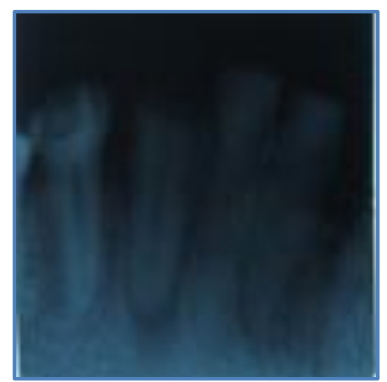

\section{Fig. e}

Fig. f) Radiograph immediately after surgical extrusion.

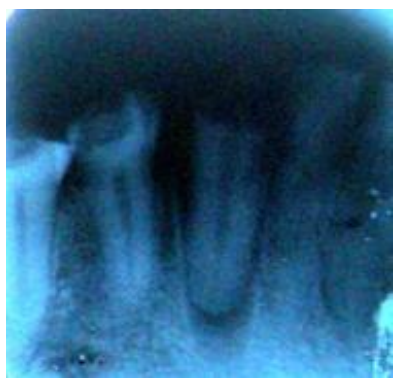

\section{Fig. $f$}


Fig. g) Radiograph 4 months after surgery displays successful root canal treatment with post $\&$ core and integrity of alveolar bone as well as re-establishment of periodontal ligament space.

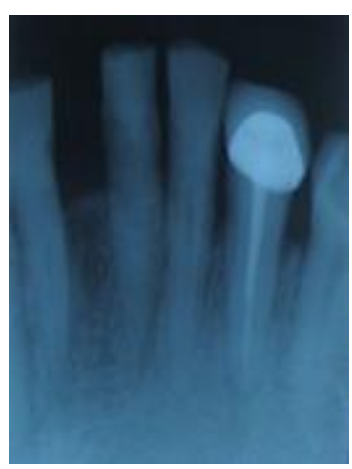

\section{Fig. $g$}

Fig. h) Ceramometal crown placement fulfills the esthetic \& functional requirements.

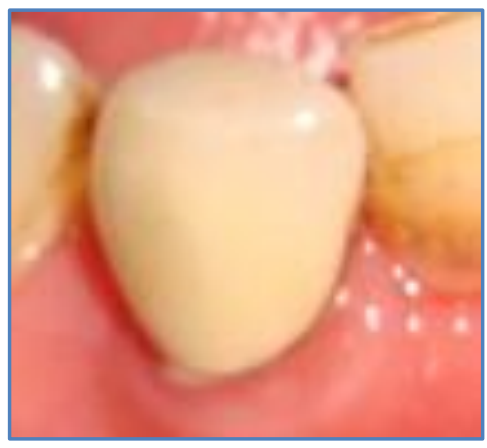

Fig. h

\section{Case 2:}

Fig. a) Initial clinical view of upper left lateral shows subgingival fracture margin \& complete loss of crown.

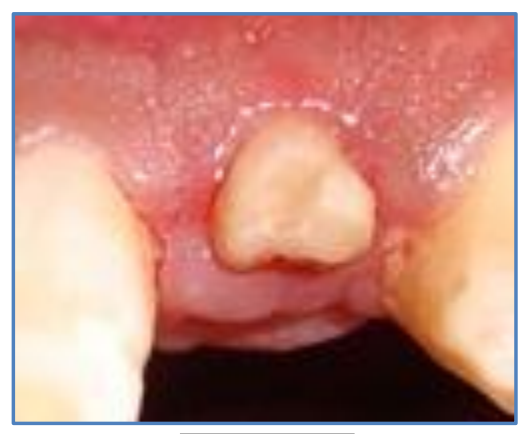

Fig. a 


\section{CASE REPORT}

Fig. b) Buccal view of coronally positioned root \& tight interproximal sutures for maintaining stability.

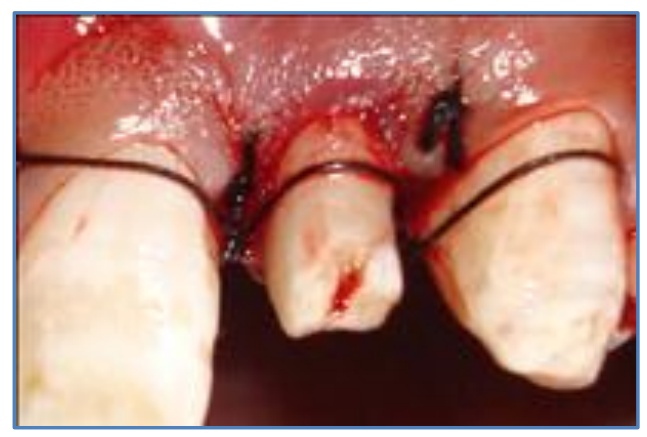

Fig. b

Fig. c) Buccal view of lateral after reconstruction with core \& post.

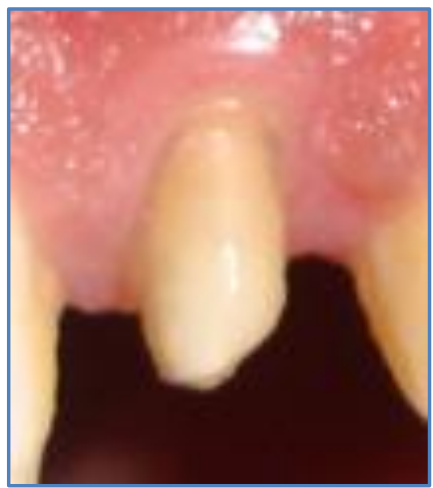

Fig. c

\section{Case 3:}

Fig. a) Initial clinical view of upper left canine shows subgingival fracture margin \& complete loss of crown.

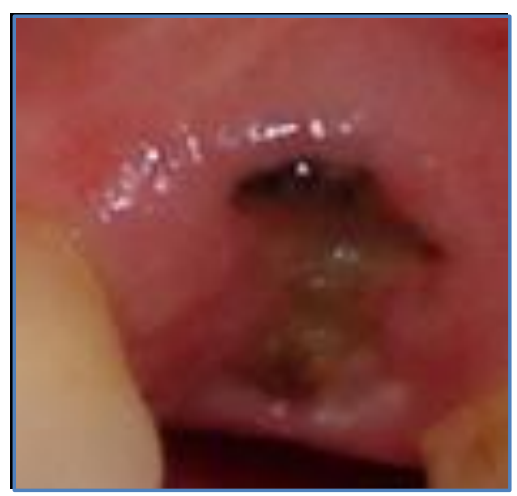

Fig. a 


\section{CASE REPORT}

Fig. b) Buccal view of canine after reconstruction with core \& post.

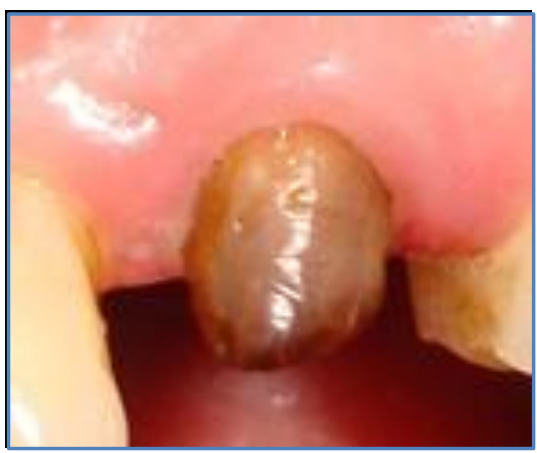

Fig. $b$

Fig. c) Ceramometal crown placement fulfills the esthetic \& functional requirements.

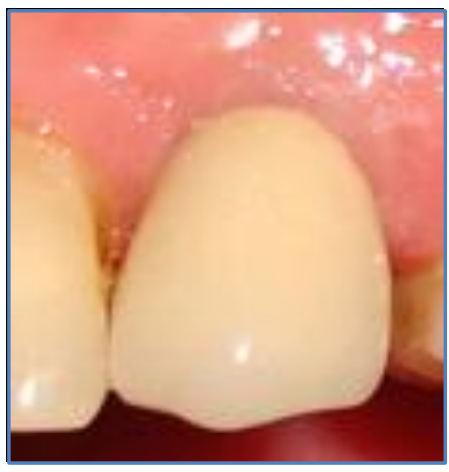

\section{Fig. c}

\section{AUTHORS:}

1. Prashant Bhusari

2. Shiras Verma

3. Amiyavardhan Jain

4. Nitin Agrawal

5. Shivam Upadhyay

\section{PARTICULARS OF CONTRIBUTORS:}

1. Professor and Guide, Department of Periodontics, Modern Dental College \& Research Centre, Indore.

2. MDS, Department of Periodontics, Modern Dental College \& Research Centre, Indore.

3. Post Graduate Student, Department of Periodontics, Modern Dental College \& Research Centre, Indore.

4. Post Graduate Student, Department of Periodontics, Modern Dental College \& Research Centre, Indore.
5. Post Graduate Student, Department of Periodontics, Modern Dental College \& Research Centre, Indore.

\section{NAME ADDRESS EMAIL ID OF THE CORRESPONDING AUTHOR:}

Dr. Nitin Agrawal, \#57, Shri Nagar Extension, Jhaad Colony, Indore-452001.

E-mail: drnitin143agrawal@gmail.com

Date of Submission: 22/05/2014.

Date of Peer Review: 23/05/2014.

Date of Acceptance: 30/05/2014.

Date of Publishing: 09/06/2014. 